\title{
UNIQUE CAVES OF THE JAIN TRADITION: UDAYAGIRI AND KHANDAGIRI
}

\section{जैन परम्परा की बेजोड़ गुफायें: उदयगिरि एवं खण्डगिरि}

\author{
Dr. Archana Rani ${ }^{1} \bowtie(D)$ \\ Head and Associate Professor, Department of Fine Arts, R G College, Meerut, India
}

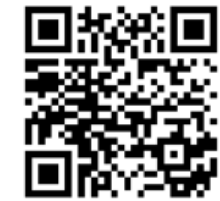

Received 20 April 2020

Accepted 16 June 2020

Published 16 June 2020

\section{Corresponding Author}

Dr. Archana Rani,

drarchana.art@gmail.com

\section{DOI}

\subsection{1/shodhkosh.v1.i1.2020.3}

Funding: This research received no specific grant from any funding agency in the public, commercial, or not-for-profit sectors.

Copyright: (C) 2020 The Author(s). This is an open access article distributed under the terms of the Creative Commons Attribution License, which permits unrestricted use, distribution, and reproduction in any medium, provided the original author and source are credited.

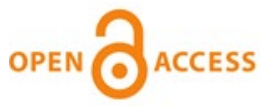

\section{ABSTRACT}

English: Udayagiri and Khandagiri caves are located near Bhubaneswar in Odisha, Madhya Pradesh. These two caves are located on two hills about two hundred meterss in front of each other. His ancient name was Kumaragiri. Here, the Jain monks who came out for nirvana used to come and do penance. Some of the caves here are natural and some are human built. Inscriptions, engraved statues, etc. in the caves indicate that it was the main pilgrimage center of Jainism in ancient times. There are eighteen caves in Udayagiri and fifteen in Khandagiri, with beautiful carvings of architecture including animal-birds, trees-belts, majestic, cosmic scenes, and religious sculptures.

Hindi: उदयगिरि एवं खण्डगिरि की गुफाएँ मध्यप्रदेश ओड़िशा में भुवनेश्वर के पास स्थित है। ये दोनों गुफाएँ एक दूसरे के सामने लगभग दो सौ मीटर की दूरी पर दो पहाड़ियों पर स्थित हैं। इनका प्राचीन नाम कुमारगिरि था। यहाँ निर्वाण हेतु निकले हुए वनवासी जैन मुनि तपस्या करने एवं रहने आते। यहाँ कुछ गुफाएँ प्राकृतिक हैं तथा कुछ मानवानिर्मित हैं। गुफाओं में शिलालेख, उत्कीर्ण प्रतिमाएँ आदि इस ओर संकेत करती हैं कि प्राचीन काल में यह जैन धर्म की प्रमुख तीर्थस्थली थी। उदयगिरि में अट्ठारह तथा खण्डगिरि में पन्द्रह गुफायें हैं, जिनमें पशु-पक्षी, वृक्ष-बेलें, राजसी, लौकिक टश्य तथा धार्मिक मूर्तियों सहित वास्तुकला के सुन्दर उत्कीर्णन हैं।

Keywords: Udayagiri, Khandagiri, Engraved, Jainism, Caves, Archeology, Culture, उदयगिरि, खण्डगिरि, उत्कीर्ण, जैन धर्म, गुफाएँ, पुरातत्व, संस्कृति

\section{1. प्रस्तावना}

कला धर्म एवं संस्कृति की वाहिका है। कला का मूलाधार सौन्दर्य की सृष्टि में परम-सत्य की खोज करना है। कला का परमोदेश्य मानवता, सुख एवं शान्ति प्रदान करना है, जो पूर्णतः धर्म पर आधारित है। धर्म सत्य को उद्घाटित करके मानव को परम सत्य का बोध कराता है। सदाचार, विनय, आनन्द, सुख एवं शान्ति धर्म के ही प्रतीक हैं। वस्तुतः धर्म को कला से बहुत कुछ मिला है। धार्मिक भावनाओं और मान्यताओं को पुष्ट करने हेतु कला की सृजन-शीलता सदैव ही अग्रणी रही है। यह कार्य आदि काल से ही विश्व की सभी समृद्ध सभ्यताओं, धर्मों में देखने को मिलता है।

भारत के प्रमुख धर्म हिन्दू, बौद्ध, जैन तथा इस्लाम हैं। भारत में जहाँ अनेक कला तीर्थ हिन्दू, बौद्ध तथा इस्लाम धर्म से सम्बन्धित हैं, वहीं जैन धर्म के प्रचार-प्रसार में भी कला में महत्वपूर्ण भूमिका निभाई है। भारत में मूर्तिकला एवं वास्तुकला की दृष्टि से अनेक जैन तीर्थ 
स्थल हैं, उन्हीं में से एक पुरातात्विक धरोहर उड़ीसा की दो पहाड़ियों पर स्थित उदयगिरि एवं खण्डगिरि की गुफाएँ हैं।

\section{2. शोध-पत्र का उद्देश्य एवं प्रक्रिया}

शोध-पत्र लेखिका ने अपने मध्य-प्रदेश भ्रमण के अवसर पर उदयगिरि तथा खण्डगिरि की गुफाएँ देखी, एक ऐसी गुफाएँ जिनका सृजन पूजन हेतु नहीं हुआ, वरन् अपने प्रभु का स्मरण करने हेतु जैन साधुओं के ध्यान एवं विश्राम करने के लिये किया गया। इन गुफाओं में स्थापत्य एवं मूर्तिकला के सुन्दर, बेजोड़ नमूने हैं तथा यह उड़ीसा प्रदेश की सांस्कृतिक प्रगति, मानव जीवन तथा धार्मिक चिन्तन की परिचायक हैं। लेखिका ने उपरोक्त गुफाओं के सौन्दर्य से अभिभूत होकर जैन धर्म की इन गुफाओं के परिचय को अपने शोध पत्र का आधार बानया हैं जिसमें जैन धर्म का परिचय, भारत में जैन गुफाएँ, उदयगिरि, खण्डगिरि पहाड़ियों पर अवस्थित गुफाओं का वर्णन एवं विशेषतायें इस लेख का वण्र्य-विषय है।

\section{3. जैन धर्म का परिचय}

जैन धर्म प्राचीन धर्मों में से एक धर्म है। जैन धर्म से तात्पर्य 'जिन' भागवान के धर्म से है और जिन उन्हें कहा जाता है जो अपने मन को जीत लेते हैं और पूर्ण ज्ञान प्राप्त कर लेते हैं। हिंसा न करना जैन धर्म का मूल सिद्धान्त है। जैन धर्म के प्रतीक चिन्ह में एक हथेली पर अहिंसा लिखा हुआ है। जैन धर्म का मानना था कि इस सृष्टि को कोई चलाने वाला नहीं है, सभी अपने अपने कर्मों को भोगते हैं। पहले जैन धर्म में मूर्तिपूजा का प्रचलन नहीं था। बाद में तीर्थांकरों के चित्र, मूर्तियाँ बनने लगीं तथा उनकीं पूजा का प्रचलन प्रारम्भ हुआ। कहा जाता है कि श्री ऋषभ देव आदिनाथ जी के द्वारा ही इस धर्म का प्रारम्भ हुआ। Hasting and Selbie (2010) ऋषभदेव के बारे में ऋग्वेद में भी लिखा है जिससे ज्ञात होता है कि जैन धर्म का अस्तित्व वेद काल से ही भी पूर्व का है। श्री अजितनाथ, संभवनाथ, अभिनन्दननाथ, सुमितनाथ, पद्मप्रभ, सुपाश्वनाथ, चन्द्रप्रभ, पुष्पदत्त, पाश्ववनाथ, नेमिनाथ, श्री महावीर जी इनके तीर्थंकर हैं, जो संख्या में चैबीस हैं। इनके दो सम्प्रदाय है- दिगम्बर और श्वेताम्बर।

जैन संस्कृति आत्मोत्कर्षवाद से सम्बन्धित है। इसलिए उसकी कला एवं स्थापत्य का हर अंग अध्यात्म से जुड़ा हुआ है। जैन कला के इतिहास से पता चलता हैं कि उसने यथासमय प्रचलित विविध कला शैलियों का प्रयोग किया है और उनके विकास में अपना महान योगदान भी दिया है। आत्मदर्शन और भक्ति भावना से सम्प्रक्त मूर्तियों, वास्तुकला एवं मन्दिरों का निर्माण किया गया और उन्हें अश्लीलता तथा शृंगारिकता से दूर रखा गया। वैराग्य भावना को सतत् जाग्रत रखने के लिए मूर्तिकला, वास्तुकला का भी उपयोग हुआ है। अध्ययन हेतु जैन पुरातत्व कला को पाँच भागों में विभाजित कर सकते हैं- मूर्तिकला, स्थापत्यकला, चित्रकला, काष्ठशिल्प और अभिलेख तथा मुद्राशास्त्र। इन सभी कला-प्रकारों में अनासक्त भाव को मुख्य रुप से प्रतिबिम्बित किया गया है। इसी में उसका सौन्दर्य और लालित्य छिपा हुआ है।

जब हम कलिंग राज्य में जैन धर्म की चर्चा करते हैं तो इसका सुव्यवस्थित प्रारम्भ सातवीं शती से जैन धर्म के तेईसवें तीर्थंकर पाश्वनाथ स्वामी द्वारा राज्य में लाया गया ज्ञात होता है। तीर्थंकर पाश्वनाथ के द्वारा आध्यात्मिक उपदेशों का ओडिशा के लोगों पर काफी प्रभाव पड़ा था। तभी ओड़िशा का तत्कालीन राजा करकुण्ड या करण्ड तीर्थंकर पाथ्वनाथ का राजकीय शिष्य था, जिसने जैन धर्म का अत्यधिक प्रचार व प्रसार किया तथा साथ ही राजा ने करकुण्ड विहार का निर्माण कराया। विहार में द्वितीय तीर्थंकर अजीतनाथ की मूर्ति बनवायी ताकि जैन धर्म का अधिक प्रचार हो सके। Camel (1992)

जैन धर्म उपदेशक महावीर स्वामी द्वारा ओडिशा भ्रमण के दौरान जैन धर्म के प्रचलन हेतु कुमारी पर्वत (उदयगिरि का प्राचीन नाम) पर विजय चक्र का निर्माण करवाया गया तथा प्रथम तीर्थंकर ऋषभनाथ की मूर्ति लगवायी गयी। जैन धर्म प्रथम शती में चेदि वंशज खारवेल के समय काल 
में अपने चरम पर था। जिसे एक समय पर राजकीय धर्म नाम दिया गया, जिसका उल्लेख शिलालेखों से प्राप्त होता है। Pradhan (2001) वास्तव में जैन धर्म ओडिशा में काफी फला-फूला।

\section{4. भारत में प्रमुख जैन गुफाएँ}

सम्पूर्ण विश्व में सर्वाधिक गुफायें आस्ट्रेलिया, दक्षिण अफ्रीका तथा भारत में पायी जाती हैं। भारत में स्थित विभिन्न कला-गुफाएँ सम्पूर्ण विश्व के लिये मार्ग दर्शक बनीं। वस्तुतः भारत में प्रागैतिहासिक काल से ही गुफाओं की सृजन परम्परा रही है। कैमूर की पहाड़ियों, सतपुडा की पहाड़ियों तथा विध्यांचल पर्वत शृंखला में अनेक गुफायें स्थापित हैं। साथ ही गुफाओं की प्राप्ति कर्नाटक, आंध्रप्रदेश, केरल, तमिलनाडु, असम, गुजरात, मध्यप्रदेश सहित भारत के अधिकांश भागों से प्राप्त हुए हैं। Chaturvedi (2000) इस प्रकार अन्य धर्मों के साथ-साथ भारत में जैन धर्म-संस्कृति की वाहक अनेक गुफाएँ हैं, जिसमें महाराष्ट्र में दिगम्बर जैन गुफाओं का समूह एलोरा मन्दिर हैं, तमिलनाडु में सित्तनवासल की गुफाएँ हैं जो जैन धर्म को समर्पित हैं। कर्नाटक के बगलकोट जिले की ऊँची पहाड़ियों पर स्थित बादामी की गुफाएँ हैं जिनमें कुछ हिन्दू धर्म तथा कुछ जैन धर्म को समर्पित हैं मध्य प्रदेश के ओडिशा में भुवनेश्वर के पास उदयगिरि एवं खण्डगिरि की गुफाएँ है जो जैन वास्तुकला एवं मूर्तिकला की हृ्टि से बेजोड़ हैं।

\section{5. ओडिशा का सांस्कृतिक परिवेश}

ओडिशा राज्य एक भौगोलिक ईकाई मात्र नहीं है, वरन् वहाँ अनेक संस्कृतियों का संगम है। यहाँ के कला इतिहास में धर्म का विशिष्ट योगदान रहा है। ओडिशा राज्य में धर्म का हष्टिकोण समन्वयात्मक रहा हैं। इसमें हिन्दू, जैन, बौद्ध, इस्लाम एवं ईसाई धर्म सहित सभी लोक धर्मों का सम्मेलन है। ऐसा माना जाता है कि ओडिशा की राजधानी भुवनेश्वर में किसी समय लगभग सात सौ मन्दिर बने थे जो समय के साथ-साथ तथा युद्धों के समय नष्ट होते चले गये। वर्तमान में सिर्फ डेढ़ सौ धार्मिक स्थलों का ही विवरण प्राप्त होता है, जिनमें गुफाएँ स्तूप, मन्दिर प्राप्त हैं। Odisha General Knowledge (2012)

\section{6. उदयगिरि, खण्डगिरि की गुफाओं का परिचय}

मौर्य काल में पर्वत काटकर गुफाओं के निर्माण की जो परम्परा प्रारम्भ हुई, उसका सर्वश्रेष्ठ उदाहरण उदयगिरि, खण्डगिरि की पहाड़ियों पर स्थित गुफाएँ हैं। ये गुफाएँ भुवनेश्वर से लगभग सातसाढे सात किलोमीटर दूर स्थित हैं। ये गुफायें कला, धर्म-संस्कृति के रुप में प्रथम शताब्दी में निर्मित हुई, जिनकी खोज 1825 ई. में ए. स्ट्रिलिंग द्वारा की गई। ये गुफाएँ जैन भिक्षुओं के रहने हेतु बनी थीं। जिनमें कुछ प्राकृतिक तथा कुछ मानवनिर्मित हैं। उदयगिरि में अट्ठारह तथा खण्डगिरि में पन्द्रह गुफायें हैं, जिनके नामकरण तथा गुफाओं की संख्या स्थानीय निवासियों ने दिये। जब ये गुफायें पुरातत्व सर्वेक्षण विभाग के सरंक्षण में आई तो उन्होंने पुरानी प्रदत्त संख्या एवं नाम वेसे ही स्वीकार कर लिए जैसे पूर्व में निर्धारित थे।

उदयगिरि की गुफाएँ लगभग 135 फुट और खण्डगिरि की गुफाएँ 118 फुट ऊंची हैं। ये गुफाएँ ईसा पूर्व दूसरी शताब्दी की हैं। ये गुफाएँ ओडिशा क्षेत्र में बौद्ध और जैन धर्म के प्रभाव को दर्शाती हैं। ये पहाड़ियाँ गुफाओं से आच्छादित हैं, जहाँ जैन साधुओं के जीवन और काल से सम्बन्धित वास्तुकला कृतियाँ हैं। इन गुफाओं का निर्माण प्राचीन ओडिशा यानी कलिंग के नरेश खारावेला ने (209-170 ईसा पूर्व के बीच) कराया था। नरेश खारावेला को अशोक सम्राट ने हरा दिया था। यद्यपि नरेश खारावेला जैन धर्म को मानते थे लेकिन सभी धार्मिक जिज्ञासाओं के प्रति उनका हृष्टिकोण उदार था। 


\section{7. उदयगिरि गुफाओं का परिचय}

उदयगिरि गुफाओं को सूर्योदय पहाड़ी भी कहा जाता है। इसमें निर्मित अधिकांश गुफाओं का निर्माण राजा खरवेल ने कराया था। जॉन मार्शल ने उदयगिरि में पैंतिस तथा मनमोहन गाँगुली ने छब्बीस गुफाओं का उल्लेख किया है। वर्तमान में यहाँ अट्ठाहर गुफायें शेष हैं, बाकि मानव व काल की क्रूरता से नष्ट हो गयी। उदयगिरि गुफाओं में भूमि को पत्थरों की समतल शिलाओं से बनाया गया है। सीढ़ीनुमा पत्थरों पर चलते-चलते अट्ठारह गुफाओं के दर्शन हो जाते हैं। गुफा संख्या एक रानीगुफा' यानी रानी की गुफा है यह गुफा ध्वनि संतुलन की विशिष्टता के लिए प्रसिद्ध है और समझा जाता है कि इसका प्रयोग मंत्रोच्चार के लिए और नाट्य प्रदर्शनों के लिए किया जाता था। यहाँ पर रथ पर सवार सूर्य देवता की भी मूर्ति बनी है।

यह गुफा सबसे आकर्षक, बड़ी एवं दो मंजिला गुफा है। इस गुफा का निर्माण राजा खारवेल ने दूसरी शती ई0पू० अर्हतों, पूज्य श्रमणों, यतियों, तपस्वियों के लिऐ कराया था जिसका उल्लेख हाथी गुफा (14वीं गुफा) के 17 पंक्ति के शिलालेख की पन्द्रहवीं पंक्ति “सकत-समण सुविहितानं च सवदिसानं '(नि) नं(?) तपसि-इ(सि) न संघियन अरहत निसीदिया-समीपे पाभारे वराकार-मसुधा पिताहि अनेक योजना-हिताही...सिलाही..." से प्राप्त होता है। Bajpai et al. (1992) गेरूए रंग से रंगी हुई इस गुफा की इमारत एक बहुत सुन्दर महल, मठ या विहार की तरह प्रतीत होती है। यह गुफा तीन ओर से घिरी है तथा दक्षिण-पूर्व से खुली है जिसके सम्मुख खुला प्रांगण है। यह गुफा कुदरती चट्टान से बनी है। जिसमें प्रचूर मात्रा में मूर्तिकला, लघु कोठरियाँ व विशाल प्रांगण है। नीचे वाली मंजिल के दायें भाग में एक कक्ष है जिसके तीन प्रवेश द्वार है और खंभों वाला बरामदा है। चतुर्भुज आकार की शिला के तीन ओर से इसकी खुदाई की गई है और दीवारों पर चित्र-बेलें बने हैं। प्रवेश स्थल पर दो संतरियों की मूर्तियों सहित इसमें कुछ सुंदर वास्तुकला के द्य हैं। इस प्रकार प्रवेश स्थल के भित्ति स्तंभों पर सुंदर चित्र-बेलें, तोरण, जीव-जंतुओं के दृश्य तथा धार्मिक और राजसी दृश्य हैं। एक नर्तकी के साथ संगीतकार को हाथ जोड़ने की मुद्रा में दर्शाया गया है। इस सम्पूर्ण गुफा में विभित्र प्रकार की मूर्तियाँ उत्कीर्ण हैं। जिसमें बैलों, पंख युक्त शेर, फल (आम), पौधे, लाताऐं, पुष्प (कमल) सहित पैनल चित्र बने हैं जिसमें मगध नरेश वृहस्पति मीत्र का राजा खारवेल के समक्ष आत्मसमर्पण, राजा खारवेल के चरण प्रक्षालित करती हुई और मंगल कलश लिये हुए सौभाग्वती महिलायें, हाथ में पूजा की सामग्री लेकर दौड़ते हुए गंधर्व, अक्रामक हाथी से युद्ध करती हुई राजकुमारी व सिंहपथ राजा की कुमारी, राजा खारवेल से रक्षा की याचना करती हुई आदि दश्यों का अंकन है।

पहली गुफा से लौटने पर दूसरी 'बाजा' गुफा मिलती है, इसे बाजाघर गुफा भी कहते हैं। इसमें दो प्रकोष्ठ और बरामदा है। बाँये प्रकोष्ठ के सामने की दीवार पूर्णतः टूटी हुई है। जिसे स्तम्भ सहारा दिये हुए हैं। स्तम्भों पर पशु-पक्षियों का अंकन है। जिसमें पक्षियों के सिर वाले जानवरों का जोड़ा एकदूसरे के विपरीत दिशा में अंकित है तथा ऊपरी भाग पर पंखों वाले जानवरों के जोड़े बने हैं। यह खम्भे ऊपर व नीचे से चैकोर व मध्य से अठभुज आकार के बने हैं।

बाजा गुफा के बायीं ओर 'छोटा हाथी' गुफा नाम तिसरी गुफा है जिसमें दो प्रकोष्ठ है जिनके द्वार पर छः हाथियों का उत्कीर्णन है। संभवतया इसी कारण इस गुफा का नाम हाथी गुफा पड़ा। Jain (2006) द्वार पर हाथियों के साथ कमल पुष्प एवं पेड़-पौधों का उत्कीर्णन है। इसी गुफा के बायीं ओर चैथी गुफा ‘अलकापुरी गुफा' है। यह भग्रावस्था में बनी दो मंजिला हैं नीचे का प्रकोष्ठ बड़ा एवं ऊँचा तथा ऊपर का छोटा एवं नीचा है। पाँचवी गुफा 'जय-विजय' नामक है जो चट्टान काटकर दो मंजिला बनी है। नीचे की प्रकोष्ठ कला विहीन है तथा ऊपर वाले में पंखयुक्त पशुओं का अंकन एवं नभचारी देव पुष्पमाला लिये उत्कीर्ण किये गये हैं। पाँचवी गुफा के आगे 'पनासा गुफा है यहाँ पहले पत्नास (कटहल) का वृक्ष रहा होगा इसलिये इसे यह नाम मिला। Jain (1975) सातवीं गफा ठाकुराणी' नाम की है जिसमें दो मंजिला गुफा में मकर, तोते, घोड़े तथा पंखदार पशु, उत्कीर्ण हैं। सातवी गुफा से लगी हुई 'पातालपुरी' नामक आठवीं गुफा बरामदे तथा चार प्रकोष्ठ से युक्त है। इस गुफा से उत्तरपश्चिम की ओर सीढ़ियाँ चढ़ने पर मंचपुरी (स्वर्गपुरी) नामक नवीं गुफा है। Agarwal (2002) यह छोटी गुफा है जिसमें भक्त, उपासक, राजा, हाथी, गन्धर्व बने है। Jain (2006) 
गुफा संख्या दस गणेश गुफा है। यहाँ पर एक चैत कक्ष है, जो साधुओं का पूजा स्थल है, रहने के लिये कम ऊँचाई वाले दो कक्ष हैं और एक बरामदा है जहाँ गणेश की उभरी हुई मूर्ति है, यहाँ पर जैन तीर्थंकर की नक्काशीनुमा मूर्ति भी हैं तथा द्वार पर दो गज मूर्तियाँ भी बनी हैं। जम्बेश्वर गुफा संख्या ग्यारह, एक छोटी गुफा है, जिसके दो दरवाजे हैं। यह गुफा कलाविहीन है, परन्तु एक लघु शिललेख है। Jain (1975)

गुफा संख्या बारह कम ऊँचाई वाली और दो दरवाजों वाली व्याघ्र गुफा है। इसका प्रवेश स्थल व्याघ्र के मुख जैसा है, जिसके ऊपर के जबड़े में दाँत दिखाई देते हैं। गुफा संख्या तेरह सर्प गुफा है।, जो बहुत ही छोटी है। यहाँ पर खारवेला को जीवन का इतिहास मगधी भाषा में अंकित है। अन्य गुफाओं में गुफा संख्या चैदह 'हाथी गुफा', गुफा संख्या पन्द्रह 'धनागार गुफा', गुफा संख्या सोलह 'हरिदास गुफा', गुफा संख्या सत्रहवी 'जगन्नाथ गुफा' तथा अठ्ठारवीं गुफा 'रसोई गुफा' है।

\section{8. खण्डगिरि गुफाओं का परिचय}

उदयगिरि की अपेक्षा खण्डगिरि की गुफायें कम आकर्षक एवं संख्या में पन्द्रह हैं। खण्डगिरि पहाड़ी की पहली और दूसरी गुफाएँ 'तातोवा' गुफा एक और दो कहलाती हैं, जो प्रवेश स्थल पर रक्षकों और बैलों तथा सिंहों से सुसज्जित हैं। प्रवेश तोरण पर तोते की आकृतियाँ हैं। गुफा संख्या तीन 'अनंत गुफा' कहलाती है, जहाँ स्त्रियों, हाथियों, खिलाड़ियों और पुष्प उठाएँ हंसों की मूतियाँ बनी हैं। गुफा संख्या चार तेन्तुली या टेंटुली' गुफा है। ओडिशा में इमली को तेतुली कहा जाता है। संभवतया यहाँ पहले इमली का वृक्ष होने से इसका नाम टेंटुली पड़ा होगा। इसके प्रकोष्ठ में प्रवेश हेतु दो द्वार है जो कलाविहिन है। गुफा चार के बायीं ओर खण्डगिरि' नाम पाँचवी गुफा हैं जिसका कुछ भाग नष्ट हो चुका है। कई खण्ड़ों में विभक्त हेने के कारण इसका नाम खण्डगिरि पड़ा होगा। Mohapatra (1981) गुफा के ऊपरी भाग में पहुँचना कठिन है। तथा यह कलात्मक भी नहीं है। खण्डगिरि गुफा के दक्षिण में 'ध्यान गुफा' नामक छठी गुफा है जो हालनुमा विशाल आकार में है जो संभवतया जैन भिक्षुओं के ध्यान हेतु प्रयुक्त होती होगी। गुफा के बायीं ओर की दिवार पर सात अक्षरों का लेख प्राप्त हुआ है जो शंखाकार है। अतः इसे शंख गुफा भी कहते है। सातवीं गुफा 'नवयुगी' गुफा है जिसमें नौ मुनियों की प्रतिमायें हैं। यह अब हॉलनुमा है जिसकी दायीं दिवार पर दो योगासन मुद्रा में मूर्तियाँ हैं। गुफा संख्या आठ से ग्यारह तक की गुफायें बाराभूंजा गुफा, त्रिशूल गुफा, अम्बिका गुफा तथा ललतेंदुकेसरी गुफा है। गुफा संख्या बारह, तेरह, चैदह के कोई नाम नहीं हैं।

\section{9. उदयगिरि, खण्डगिरि गुफाओं का कलात्मक सौन्दर्य}

उदयगिरि-खण्डगिरि पहाड़ियों का युग्म समूह अपनी प्राचीन जैन गुफाओं एवं उसमें प्रदर्शित कला शिल्प की दृष्टि से ओडिशा में प्रथम शती ई0 के कला इतिहास का महत्वपूर्ण केन्द्र है। इन गुफाओं में कलात्मक दुष्टि से हुआ उत्कीर्णन कार्य अत्यन्त विशिष्ट और सौन्दर्यात्मक है, जिसके अन्तर्गत रुप संरचना में गहराई एवं सक्षम शिल्पधर्मिता के गुण स्पष्ट परिलक्षित होते हैं। यूँ तो इन गुफाओं के निर्माण का कारण जैन ऋषियों को आवासीय सुविधा पहुँचाना था, परन्तु फिर भी इन गुफाओं की कला देशव्यापी कला-आन्दोलन का अंग बन गयी है। य़द्यपि संरचनात्मक हृष्टि से यह अजन्ता, एलोरा के समान उत्कृष्ट नहीं हैं, लेकिन कलात्मक हृष्टि से महत्वपूर्ण हैं। इन गुफाओं का निर्माण अधिकतर शिलाओं के ऊपरी भाग में होता था और गुफाओं के आवास साधना और प्रार्थना के लिए सूखे वाले स्थान होते थे, जहाँ वर्षा का पानी नहीं ठहरता था, इसके साथ बरामदा या आँगन होता था। छोटी-छोटी सुविधाओं की भी व्यवस्था होती थी। हालांकि छत की ऊँचाई कम होती थी और कोई व्यक्ति सीधे खड़ा नहीं हो सकता था। मुख्य रुप से ये विश्राम स्थल या शयन कक्ष थे। एक ही कक्ष में बहुत साधु रहते थे। कक्ष में एक खास बात थी कि प्रवेश स्थल के सामने की ओर का फर्श ऊँचा उठा हुआ है, जो शायद सोने के समय सिरहाने का काम देता था। ये कक्ष तंग और सपाट होते थे और इनके प्रवेश द्वार पर वास्तुकला कृतियों का उत्कीर्णन होता था। जिसमें विभित्र प्रकार के 
दरबार के द्य, पशु-पक्षी, शाही जुलूसों, शिकार अभियानों और दैन्य जीवन के टृश्य होते थे। ये लेख ब्राह्मी लिपि में हैं और जैनियों के मूल मंत्र-णमोकार मंत्र से शुरु होते हैं। Johrapurkar (n.d.) इसके बाद राजा खारवेला के जीवन और कार्यों से सम्बन्धित हश्य हैं, जो सभी धार्मिक व्यवस्थओं का सम्मान करते थे और धर्म स्थलों का जीर्णोद्धार करते थे। अलग-अलग गुफाओं पर उनके संरक्षकों के नाम हैं। अधिकतर संरक्षक राजा के वंशज हैं। कलिंग विजय के बाद जब अशोक का शासन हुआ और राजा खारवेला की सभी संपत्तियों पर उनका अधिकार हो गया, धीरे-धीरे जैन धर्म के स्थान पर बौद्ध धर्म का प्रभाव बढ़ने लगा। Jain (1960) इन गुफाओं में लगभग बीस शिलालेख प्राप्त हुए हैं। शिलालेखों में गुफाओं को 'लेना' कहा गया है। और इन्हें न जाने कितनी पूर्णिमा वाली चाँदनी रातों में बनाया गया था। गुफाओं के मुँह दरवाजों जैसे हैं, जहाँ से दिन के समय सूरज की रोशनी आ सकती है और पथरीले फर्श गर्म रहते हैं। रात को चाँद की रोशनी गुफा में आती है और गुफाओं में उजाला रहता है। इन गुफाओं में साधु लोग आकर रहते थे, जो संसार को त्याग कर अपने तन और मन की शक्तियों के प्रवाह से निर्वाण के लिए तपस्या करते थे। सुगन्धित फूलों, चहचहाते पक्षियों, पत्तों की सरसराहट, उजली धूप और शीतल चंद्रमा के सात्रिध्य में वे प्रकृति के साथ एक रुप हो जाते थे। इन गुफाओं में बैठकर साधुजन शांति से समाधि लगाते थे और कठोर तपस्या करते थे। विद्वान लोग भी सत्य, शांति, मोक्ष और सौन्दर्य बोध के लिये यहाँ आते थे। ये गुफायें तत्कालीन मानव के समर्पण, राजनैतिक युद्ध एवं धार्मिक प्रवृतियों के प्रमाण हैं। ये गुफाएँ केवल हश्याकंन से फली-फूली नहीं थी, अपितु दश्यों के आस-पास चारों ओर दीवार पर फूल-पत्ती, वृक्ष, आम्र फल, कमल पुष्प लताओं व विभित्र जानवरों का अलंकरण भी प्राप्त होता है। यह अलंकरण द्यश्य उत्कीर्णन को कलात्मक विकास में सहभागिता प्रदान करता है। इन्हीं कारणों से द्य की आकृतियाँ अलग-अलग समूहों में बँटी हुई सी प्रतीत होती हैं जो अलंकरण संपुंजन को समग्र एवं एकत्र निरूपण में सहयोग करता है। इस प्रकार यहाँ न केवल धार्मिक, अपितु लौकिक विषयवस्तु का अंकन भी हुआ है। धार्मिक मूर्तियों में जैन व हिन्दू धर्म से सम्बन्धित मूतियाँ प्राप्त हुई हैं जैसे कि खण्डगिरि गुफाओं से प्राप्त तीर्थंकर मूर्तियाँ व गणेश गुफा से प्राप्त गणेश जी की मूर्ति। इसी प्रकार गुफाओं में लौकिक विषय जैसे-राजारानी का वैभव पूर्ण जीवन दश्य, आखेट हश्य, युद्ध हश्य, स्त्री हरण वाले हश्य, द्वार पाल व पूजा हश्य आदि प्रकार की मूतियाँ हष्टिपात होती हैं।

\section{0. निष्कर्ष}

ओडिशा उदयगिरि-खण्डगिरि गुहायुग्म जैन धर्म विषयक कला-वैभव एवं इतिहास की साक्षी हैं जो समय के प्रतिस्पन्दन के साथ धर्म, स्थापत्य के सौन्दर्य को प्रदर्शित करती है। यह गुफा मन्दिर चैत्य अर्थात् पूजा स्थल नहीं है वरन् जैन भिक्षाओं के ध्यान एवं विश्राम हेतु बनीं है। इन गुफाओं में अर्द्ध उत्कीर्णित व पूर्ण उत्कीर्णित मूर्तियाँ अद्भुत आकार से सुगठित, छाया-प्रकाश अनुरुप उतार-चढ़ाव की सुन्दर अभिव्यक्ति से प्रतिपादित एवं गत्यात्मक चेष्टाओं की उत्कृष्ट प्राणवत्ता से भरे हुए हैं। अतः यहाँ की कला अपने समय की अधिक विकसित व परिष्कृत कला थी जो कि वर्तमान में दो हजार वर्षों पश्चात् भी अपना वैभव स्थापित किये हुए है। इस प्रकार राजा खाखेल ने गुफाओं के माध्यम से जैन धर्म के प्रचार-प्रसार में अपना अनूठा योगदान दिया है। गुहायुग्म में उनके धर्म और स्वभाव का सुन्दर अंकन दृश्यमान होता है। वस्तुतः जैन परम्परा की हष्टि से उदयगिरि एवं खण्डगिरि की गुफायें बेजोड़ है। 


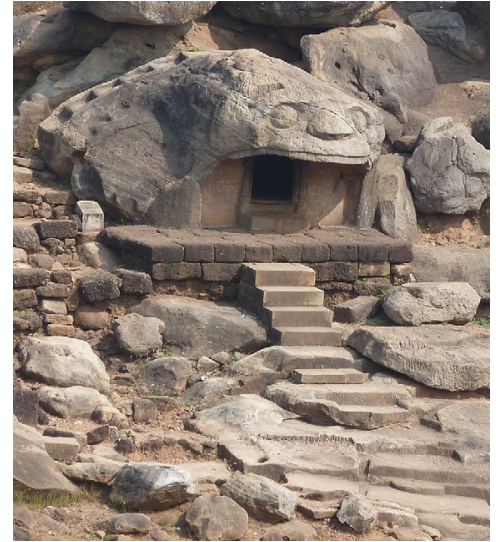

चित्र 1 गुफा संख्या 13 - सर्प गुफा

Picture by Author

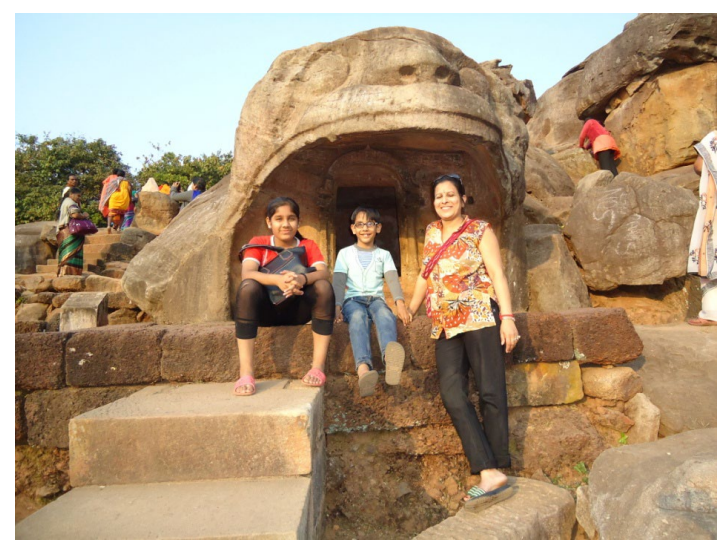

चित्र 2 लेखिका - सर्प गुफा के सामन

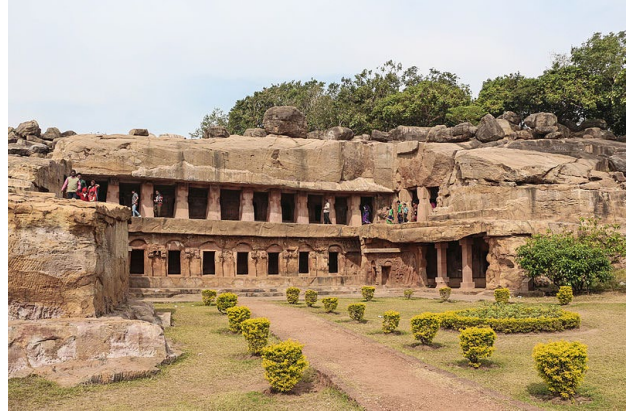

चित्र 3 उदयगिरि, गुफा संख्या 1 - रानी गुफा Picture by Author

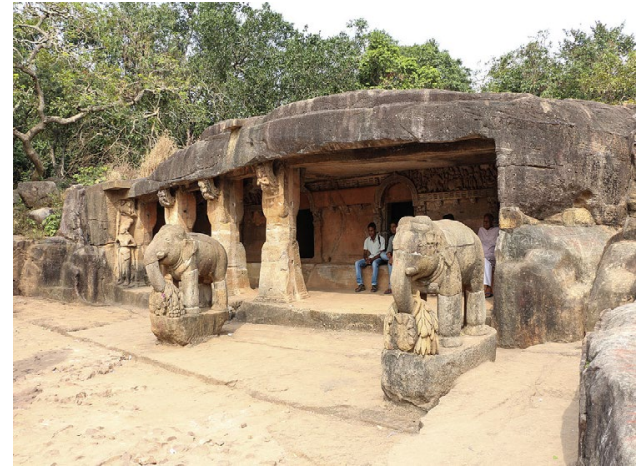

चित्र 5 उदयगिरि, गुफा संख्या - 3 छोटा हाथी गुफा Picture by Author

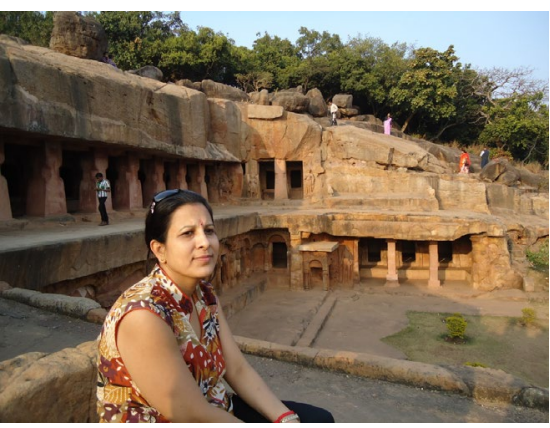

चित्र 4 उदयगिरि, रानी गुफा के सामने

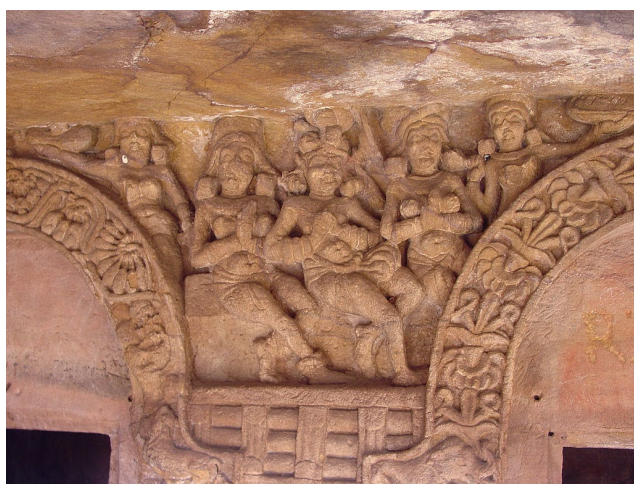

चित्र 6 गुफाओं पर कलात्मक उत्कीर्णन 


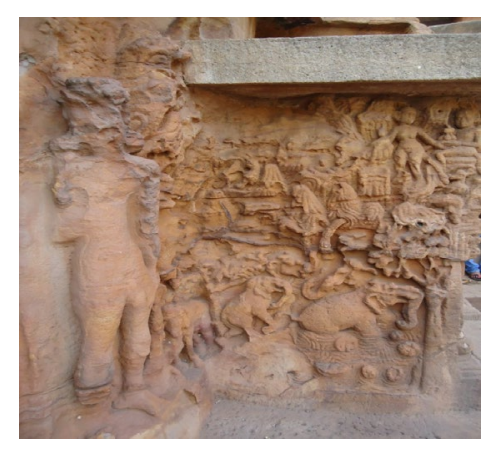

चित्र 7 गुफाओं पर कलात्मक उत्कीर्णन Picture by Author

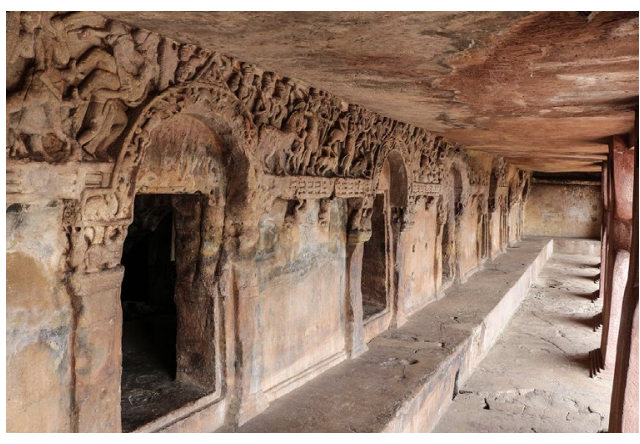

चित्र 8 रानी गफा के प्रांगण पर कलात्मक उत्कीर्णन

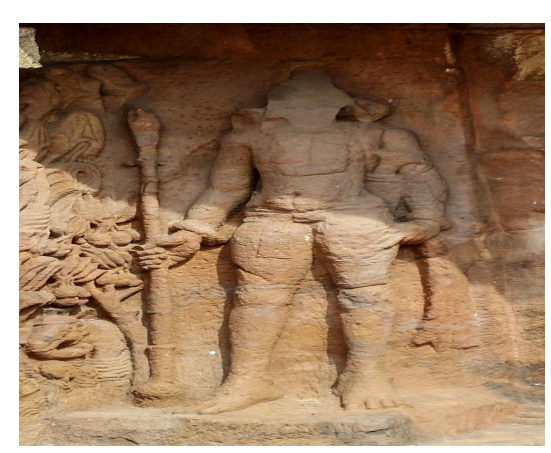

चित्र 9 उदयगिरि, गुफा पर अंकित योद्धा की मूति Picture by Author

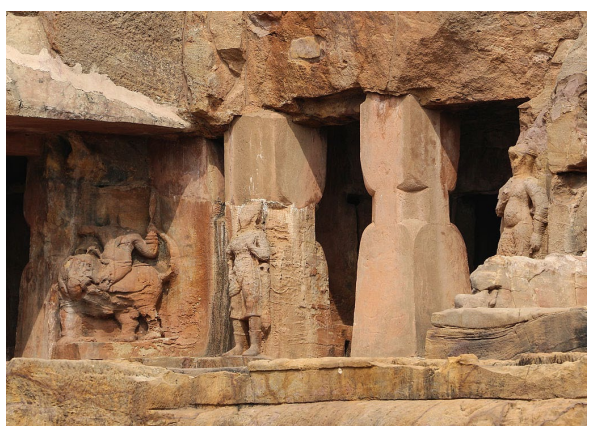

चित्र 10 गुफा के खम्मों पर उत्कीर्णन

\section{REFERENCES}

Agarwal, P.K. (2002). Prachin Bhatiya kala evam vastu [Ancient Indian Art and Architecture]. Varanasi University Publications, 16. http://wwwlib.tufs.ac.jp/opac/recordID/catalog.bib/BA70452033

Bajpai, K. D., Agarwal, K.L., Bajpai, S. K. (1992). Aitihasika Bhatiya Abhilekha. [Historical Indian Records]. Jaipur Publishing Scheme, 107. http://wwwlib.tufs.ac.jp/opac/recordID/catalog.bib/BA46272625

Camel, P.K.V. (1992). Encyclopaedia of India-Odisha, New Delhi. Reema Publishing House, 74. http://www.odishaarchives.nic.in/node/168755

Chaturvedi, R. (2000). Jain Aagam Itihaas Awam Sanskrti [Jain Advent History and Culture] (1st ed.). New Delhi, Anamika Publishing \& Distributors (Pvt.), 18.

Hasting, J. and Selbie, J. A. (2010). Encyclopaedia of Religion and Ethics. America: Kesslinger $\quad$ Publishing, (18), 265. https://books.google.co.uk/books?id=5I4lcAAACAAJ

Jain, B. (1975). Bharat Ke Digambar Jain Tirth Part 2 [Digambar Jain Shrine of India Part 2]. Bombay. Bharatvarsha Digambar Jain Teerth Shetra Committee, 209210. https://jainebooks.org/books/10317/bharat-ke-digambar-jain-tirth-part-2 
Jain, H. (1960). Bhatiya Sanskriti Me Jain Dharm Ka Yogdan [Contribution of $\begin{array}{llll}\text { Jainism in } & 332 .\end{array}$

https://www.jainebooks.org/books/14322/bhartiya-sanskriti-me-jain-dharm-kayogdan

Jain, L. (2006). Orissa Ke Jain Mandir, Bhuvaneshvar [Jain Temples of Orissa, Bhubaneshwar], Ankita Graphics, 77

Johrapurkar, V. (n.d.). Jain Shilalekha Samgraha Bhag 1 Prastavana [Jain Inscription Collection Part 1 Preface], 13

Mohapatra, R.P. (1981). Udayagiri Khand Khandgiri Caves. Delhi, D.K. Publications, 180. http://www.worldcat.org/oclc/8069640

Odisha General Knowledge (2012). Odisha: Bright Publishing, 60

Pradhan, S. (2001). Rock Art in Odisha, New Delhi. Aryan Books International, 74. https://amzn.to/35pXy1E 